\title{
The crucial question of standardisation when measuring drug consumption
}

\author{
Claire Chauvin ${ }^{\mathrm{a} *}$, François MADEC ${ }^{\mathrm{a}}$, Didier GuILlEMOT $^{\mathrm{b}}$, \\ Pascal SANDERS ${ }^{\mathrm{c}}$
}
a Agence Française de Sécurité Sanitaire des Aliments, Site de Ploufragan, Unité d'Epidémiologie Porcine et Assurance Qualité, Zoopôle, BP 53, 22440 Ploufragan, France
${ }^{\mathrm{b}}$ INSERM, Unité 21, 16 avenue Paul Vaillant Couturier, 94807 Villejuif Cedex, France
${ }^{c}$ Agence Française de Sécurité Sanitaire des Aliments, Site de Fougères, Laboratoire d'Études et de Recherches sur les Médicaments Vétérinaires et les Désinfectants, La Haute Marche, Javené, 35133 Fougères, France

(Received 22 January 2001; accepted 23 July 2001)

\begin{abstract}
The reliability of drug consumption studies will depend on agreement on an international unit of measurement and the provision of accurate descriptions of patterns of use. This measurement unit should permit comparisons between countries and periods of time. Different units have been proposed and published. Consumption may be expressed in terms of pharmaceutical firm turnover, therapeutic costs, weight (total weight or dose equivalent), treatment doses such as defined daily dose and prescribed daily dose, or as number of items or packages sold. The advantages and disadvantages of the different evaluation units used in veterinary medicine are reviewed.
\end{abstract}

drug consumption / unit of measurement / veterinary medicine / drug statistics / DDD

Résumé - Évaluation de la consommation médicamenteuse : le problème de la standardisation. L'étude des consommations médicamenteuses requiert une unité de mesure internationale applicable aux différentes méthodes de recueil des données et permettant une description la plus complète possible des consommations. Les comparaisons géographiques, temporelles et entre usages doivent également être possibles. Différents systèmes unitaires ont été développés selon ces différents critères et impératifs. Ces unités peuvent être économiques (chiffres d'affaire des firmes pharmaceutiques ou coûts thérapeutiques), pondérales (poids total ou converti en dose active), liées au traitement (dose définie journalière, dose quotidienne prescrite) ou pratiques (nombre de conditionnements vendus). Une revue des différentes unités utilisées en médecine vétérinaire est ici présentée.

consommation médicamenteuse / unité de mesure / médecine vétérinaire / DDD

* Correspondence and reprints

Tel.: (33) 2960162 22; fax: (33) 2960162 23; e-mail: c.chauvin@ ploufragan.afssa.fr 


\section{Table of contents}

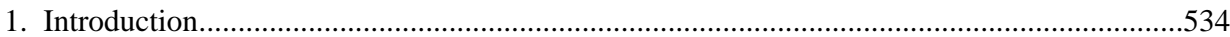

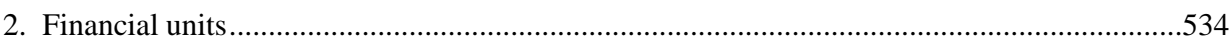

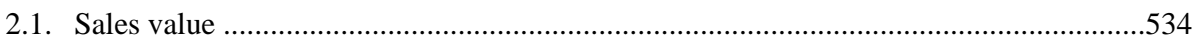

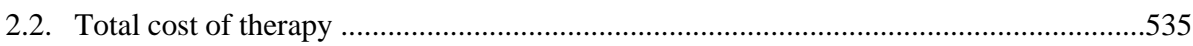

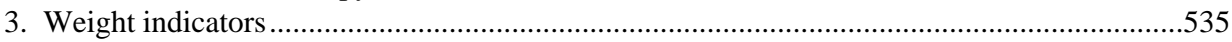

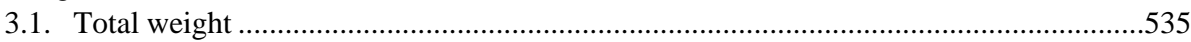

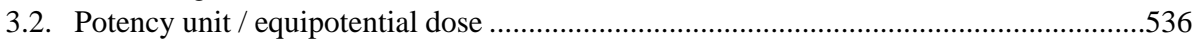

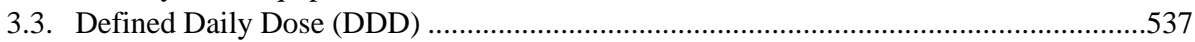

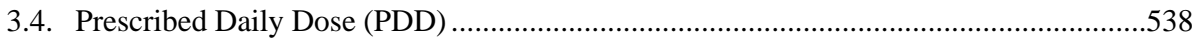

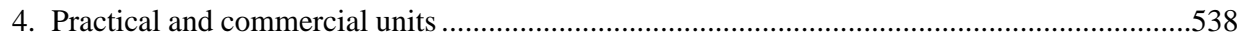

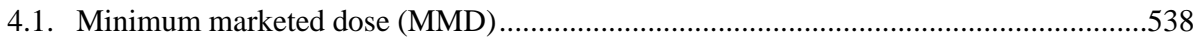

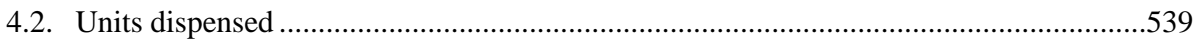

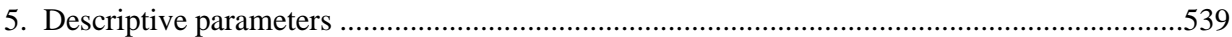

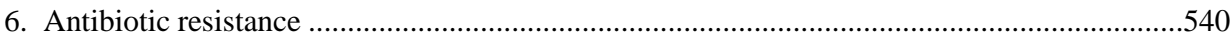

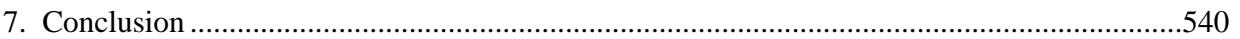

\section{INTRODUCTION}

Knowledge of drug usage patterns and amounts consumed has been of interest for many years, primarily to the pharmaceutical industry, for financial and commercial purposes, but also to health regulation authorities and the scientific community. There is now a need in veterinary medicine to know which drugs are administered to foodproducing animals and, also, to determine why, when and how they are used.

Particular emphasis is being placed on antibiotic consumption so as to optimise the use of antibacterials, to look for correlations between usage and the emergence of resistance and to impede the spread of such resistance. Collection of antibacterial drug usage data has been widely recommended in both human and veterinary medicine [1].

However, any studies of drug consumption come up against complex problems associated with data acquisition and processing. They are further hindered by the heterogeneity of the measures available, e.g. kilograms or number of marketed packages. The most difficult step, however, is to determine an appropriate method and a suitable unit of measurement. It should be possible to use such a unit to describe and compare drug consumption in a wide variety of situations in both veterinary and human medicine, for a range of purposes such as disease prevention, disease treatment or growth promotion, and also in different areas and over time.

Several units of measurement have been used and described in the literature. Here, we review their advantages and disadvantages.

\section{FINANCIAL UNITS}

\subsection{Sales value}

This unit of measurement has been widely used in drug utilisation studies [16]. The first quantitative studies of drug consumption were carried out by pharmaceutical industries for commercial purposes i.e., to determine the market share of the company's products. This unit is, therefore, still in use in this economic sector and in all longitudinal studies which include these initial data. In France, one figure that companies must report to the French Health Products Safety Agency is turnover expressed as the duty-free factory price [2]. This unit can thus be used in France to compare 
antibiotic use in human therapy, veterinary therapy and animal growth promotion [11].

However, several difficulties may be encountered with an economic unit of measurement. For example, a bias is induced by the variance between sales and consumption. In addition, the costs incurred between drug production and consumption are modified by the very nature of transactions. A correction factor is sometimes used. In their study of duty-free turnover of antibiotics in herds, Gorse and Janet [20], added 20\% to the firm's purchasing costs. A financial unit does not allow comparisons of the consumption of active substances of different economic value. Active substances are often more expensive when used in human medicine than in veterinary medicine. The anti-infectious agents consumed in the former are usually new active substances, whereas those used as feed additives are earlier, cheaper ones [44]. Moreover, national consumption based on sales value, including both prices and quantities, simply reflects the proportion of a country's wealth attributed to drugs. Thus, comparisons of sales figures between countries may have to take into account foreign exchange rates, and economic disparities.

\subsection{Total cost of therapy}

Although this unit is also based on the economic value of drugs, it allows a better approach to the amounts consumed and expresses the notion of treatment, which is the purpose of consumption.

In hospitals, the cost of therapy is obtained from pharmaceutical and accounting services, by dividing health expenditures by the number of patients treated. This is an excellent parameter for studying the management of health expenditure and its evolution.

In breeding herds, "health maintenance expenditure" provides a good and readily available economic and accounting indica- tor of disease patterns, expressed in monetary units per time unit per animal sold or kilogram of meat sold, or kilogram of milk, or breeding animal $[19,31,32]$. This indicator can be used to analyse the distribution of expenditure in a given production unit, according to therapeutic class, source of intake, and over time.

Obviously, this unit does not accurately express the number of treatments consumed. This was highlighted in a hospital study [3]. From 1995 to 1998 , the number of defined daily doses (DDD, cf. infra) of anti-infectious agents per 100 hospitalisation days (HD) increased in the Nord Pas-de-Calais area (from 12.9 to $14.8 \mathrm{DDD} / 100 \mathrm{HD}$ ), whereas the total cost of therapy per patient decreased (from $202 \mathrm{FF}$ to $163 \mathrm{FF}$ ). When unknown, the economic value of a treatment is difficult to assess and drug consumption cannot be easily quantified with this unit. However, it is of great help to health authorities when they are trying to produce national health policies to reduce costly over-medication. With the same aim, breeders use this unit to determine the proportion of their production costs associated with health expenditure.

The cost of therapy is still heavily reliant on the disadvantages of monetary units, as it depends on the price variability of the raw substances. In 1980, the drugs consumed in rabbit production systems were cheaper than those consumed on pig farms. The consumption value for pig farms was therefore overestimated [20]. Inter-species, geographical and longitudinal comparisons would clearly have no value.

\section{WEIGHT INDICATORS}

\subsection{Total weight}

Total consumption or sales can be expressed in terms of active substance weight, in kilograms $(\mathrm{kg})$ or tons, and at a national or regional level. Although the total weights in tonnage are known by the 
pharmaceutical firms, the latter are not legally required to transmit such information. Both national and international organizations are now compiling data on the use of antibiotics on animals in Europe [4, 18], such as the Danish, Finnish and Swedish authorities [5-7, 9]. The same weight unit can be used whatever the consumer species, and each drug can be expressed in terms of active ingredient weight [21]. However, such a methodology only provides a realistic evaluation of drug consumption if drug usage is related to the potential consumer population, i.e. number of animals at risk [6]. It is difficult to accurately determine this population, even though some statistics do exist. An approximation may be necessary, such as adding together individuals that died or were slaughtered during the period and those living at the end of the year [47]. Breaking down consumption according to animal species is only possible for a few drugs, as a single active substance may be used in several species [9].

A more detailed analysis, relating consumption to the metabolic body weights (based on average live weight) of potential consumers (animals or humans), could be carried out [7, 18, 20, 43, 44, 47]. This indicator gives a more exact idea of drug use and may allow comparisons between different species. In 1990, $80000 \mathrm{~kg}$ of antibiotic active substances were administered to the Netherlands population and $300000 \mathrm{~kg}$ for veterinary usage. The total amount of antibiotics used, in $\mathrm{mg} / \mathrm{kg}$ body weight/year, showed that the same level of selective pressure was exerted on the bacterial flora of the animal population by the veterinary usage of antibiotics as that exerted by the medical usage of these drugs on human bacterial flora [44]. A similar methodology applied to animal and human antibiotic consumptions in Europe, showed a 4.5 fold higher consumption in $\mathrm{mg} / \mathrm{kg}$ in the human population [43]. These calculations were, however, based on approximations both of the consumer population and of the average body weights (using a mean human body mass of $60 \mathrm{~kg}$ overestimates the total human body weight [43]).

Studying the total weight consumption of a particular therapeutic class presents another bias, as it assumes that each active substance has the same therapeutic potency. Usually, the proportions of each active substance differ both in the total intake per species and with time [43]. Thus total weight consumption will not reflect the same therapeutic intensity because the biological activity per weight unit differs from drug to drug. For example, comparing consumption in kilograms can be misleading in terms of treatment incidence [18]. Also, if a substance requiring high doses to be completely effective is substituted by a more active substance, a false impression of a decrease in total drug consumption may be given [37]. A different situation may appear when information given in kilograms of active substance is translated into units of potency equivalent.

\subsection{Potency unit / equipotential dose}

A conversion factor related to the dosage of the active drug substance needs to be used to translate the amount consumed into an expression of the therapeutic effect. Two units have been developed for this purpose.

Equipotential dose (ED), as reported by Merlo et al. [36], was first used to study the treatment of hypertension. The consumption of each active substance was expressed as doses/amounts having the same potential effect on blood pressure. The therapeutic effect was thus introduced, but no information was given on the number of consumers or treatments. This unit is close to the DDD and brings out comparable results.

Mudd et al. [37, 38] introduced the potency unit to study the development over time of antibiotic consumption in animals in Sweden. A standard dose was defined, that of tetracycline, and designated 
"tetracycline unit". A correction factor was then defined for each active substance according to the doses used. The dosage correction factor for macrolides is equal to 6 or 5 , depending on the study $[23,37,38]$. The standard dose for each substance group was based on the dominant substance. A tentative dose of $50 \mathrm{ppm}$ was fixed for feed additives in livestock production, which assumed a certain level of feed consumption [23].

\subsection{Defined Daily Dose (DDD)}

In human medicine, the DDD of a drug is considered to be the average maintenance dose in adults when it is used routinely for the major indication [34]. The DDD is an expression of the dose size of an active substance per patient and per day, and is thus independent of formulation, package size and sales price. The DDD for a drug is usually established just after the drug has been put on the market and is revised after three years observation of its use. A DDD is a compromise based on a review of the knowledge and recommendations available from different countries. DDDs are determined by an independent scientific committee answering to the WHO Collaborating Center for Drug Statistics Methodology [46]. A DDD can be revised in accordance with the development of practices and pharmacokinetic knowledge.

This unit has been used for many years in numerous studies: descriptions of human consumption, geographical comparisons of drug use, longitudinal studies, and drug use at the population or individual levels.

Consumption within a population is usually expressed as the number of DDD per 1000 inhabitants per day, calculated as follows:

$\frac{\text { amounts of drug sold in one year }(\mathrm{mg})}{\mathrm{DDD}(\mathrm{mg}) \times 365 \text { days } \times \text { number of inhabitants }} \times 1000$ inhabitants
$=$ number of DDD $/ 1000$ inhabitants/ day.

The number of DDD reported in relation to population and time affords an estimate of the proportion of drug users within a population that might have received a particular drug treatment, provided that the DDD of that drug concurs with the prescribed daily dose. This method may be used to estimate the prevalence of diseases like diabetes, for which there is a close relationship between drug consumption and disease prevalence. For drugs used discontinuously, the number of days in a period of treatment is taken into consideration and gives a better estimate of the proportion of consumers [45].

For hospital use, DDD per 100 bed-days has been chosen as a unit of measurement [3, 30]. The number of bed-days is defined as the average number of patients in the hospital or ward per day.

Although this unit of measurement has only recently been transposed to veterinary medicine, its interest has already been emphasised. The first study, based on a DDD expression of veterinary antibacterial drug usage for mastitis in cattle in Sweden and Norway, has been published. The data were obtained from drug wholesaler statistics [21]. For intramammary drugs administered by means of single-dose applicators, the $\mathrm{DDD}_{\text {cow }}$ was defined as one applicator. The antibacterial preparations included in the study were injectable veterinary pharmaceuticals for systemic administration, with bovine mastitis as one of the indications. $\mathrm{DDD}_{\text {cow }}$ for the various injectable drugs were derived from doses recommended in the Norwegian and Swedish compendiums, respectively, for veterinary medicines. Dosages were defined for a $500 \mathrm{~kg}$ cow which, although not identical to the average cow weight in Norway and Sweden, was not too far off and made calculations easier. For the combination preparations, $\mathrm{DDD}_{\mathrm{cow}}$ were estimated for the main substance; trimethoprim for the trimethoprim-sulphonamides or procain penicillin for the procain penicillin-dihydrostreptomycine combinations, as recommended in human medicine. To evaluate trends in the use of antibacterial drugs in 
dairy cows, treatment incidence or incidence of use was then calculated as:

$$
\frac{\text { amountsof drug sold in one year }(\mathrm{mg})}{\mathrm{DDD}_{\text {cour }}(\mathrm{mg}) \times 365 \text { days } \times \text { number of cows at risk }} \times 1000 \text { cows a trisk, }
$$

expressed in number of DDD cow $500 \mathrm{~kg} / 1000$ cows at risk / day.

The main problem encountered when using DDD in veterinary medicine is due to dosage variations between different animal species. The evaluation of consumption of drugs approved for use in several species is thus difficult, and comparisons of consumption in different species quite impossible. Besides, few DDD have been defined to date in veterinary medicine [22].

Another pitfall encountered with DDD is its inadequacy when trends alter. If the dosages used over time are increased with the same number of prescriptions and without changing the DDD, then the total consumption expressed in DDD/1000 inhabitants/day will decline [13]. This can be misleading, since a decline in consumption of the substance or therapeutic class can occur even if the number of prescriptions does not show any fluctuation. Differences from 4 to $80 \%$ have been observed between the real number of consumers and the number estimated by use of DDD [45]. In such cases, the DDD can be modified. About twenty DDD were changed during 1990 [41]. Changes are not desirable if DDD is to be used as a system of reference.

Geographical studies have encountered the same difficulties as longitudinal ones since trends may differ greatly between countries. The DDD remain the same but dosages and duration of treatment may vary from one country to another. Interpretations of the total amounts translated into DDD or DDD/1000 inhabitants/24 h will then be wrong.

However, the DDD is not a recommended or prescribed dose, but simply a technical unit of measurement and comparison, to convert drug consumption figures from different sources into comparable units within time and geographic area and in a medical context.

\subsection{Prescribed Daily Dose (PDD)}

This unit has been used especially in studies to determine prescribing patterns or when data are collected at the prescription stage. It is a good complement to the DDD as it provides additional information for interpretation of the latter. The PDD describes doctors' habits, not experts' opinions and may differ for reasons such as poor evaluation of the patient's weight, an adaptation by default to packaging, or application of a different therapeutic regimen, etc.

One French study revealed the frequent prescription of lower dairy doses than recommended [24]. Discrepancies between DDD and PDD differ from substance to substance: the DDD of naproxen is $500 \mathrm{mg}$, whereas the observed PDD is $792 \mathrm{mg}$. The DDD and PDD of metoprolol are 200 and $130 \mathrm{mg}$, respectively [45]. For most drugs, the difference is minimal when PDD is calculated at the population level, but different daily dosages may be observed between prescriptions and between countries [29]. The PDD should thus explain observed geographical differences in DDD values. When the DDD and PDD differ, the latter is better for evaluating the number of consumers or the average duration of treatment [27].

Unfortunately information about PDD is often difficult to obtain as it is not usually available for the entire population or on a continuous basis. Such information is often used in selective studies, collected through specific investigations conducted by pharmacists or physicians.

\section{PRACTICAL AND COMMERCIAL UNITS}

\subsection{Minimum Marketed Dose (MMD)}

This unit was first developed to study anxiolytic drug-use intensity [39]. It is the 
minimum dose that will produce a desired therapeutic effect. In practice, it corresponds to the minimum dose marketed by the manufacturer. Unlike DDD, MMD is neither internationally accepted nor homogeneous; it varies in accordance with firms, manufacturers' wishes, and formulation progress [36].

\subsection{Units dispensed}

Units dispensed are identical to the number of packages or items sold. Obviously there is great variation in the amount of active substance per item [29]. This unit is, however, readily accessible within firms for the monitoring of sales. In France, companies must report such sale figures to the French Agency for Health Products Safety. Since 1991, packaging sizes have been standardized for each antibiotic family [2].

Bogle and Harris [10] used the item unit to assess its validity as a measure of the volume of a drug prescribed. In fact, an item may stand for any number of tablets, milliliters of liquid or other unit. It is an unsuitable measure for prescribing volume.

The use of antibiotics in the community in Spain has been described by Bremón et al. [12] in terms of number of packages and also in weight of active substance. The number of packages sold was used to calculate equivalents in weight of active drug ingredient and defined daily doses per 1000 inhabitants per day. For the period studied (1987-1997) the number of packages sold declined, whereas a gradual rise in consumption was observed when sale figures were expressed as weight or DDD. These differences between units of measurement were due to modifications in the formulation (weight of active substance) or type of packaging during the test period, e.g. a greater weight of active substance per unit or an increase in the number of units per package. Data would be misleading if this package-unit indicator alone was used to evaluate drug consumption.

\section{DESCRIPTIVE PARAMETERS}

Several parameters have been developed to complete the quantitative description of drug consumption.

The prescription rate is the percentage of patients receiving a given treatment in a given population [42]. This imprecise definition can be interpreted in several ways, depending on the populations studied and measurement practices. Prescription rate is close to therapeutic intensity, calculated as the number of DDD used per 1000 persons par day [27].

In animal rearing, the number of treatments is a good technical and economical indicator, but population size and structure can fluctuate over time, at least in pig production. The term animal-year has been introduced to standardise measurements [33]. Dunlop, recording individual treatments [17], describes the individual-animal treatment rate with the following ratio:

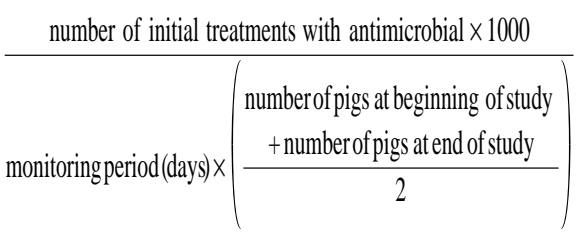

The prescription rate is the ratio between the population to which the treatment is prescribed and a reference population. Depending on the study objectives, this reference population can be the entire animal population of a country or only the animals "at risk", i.e. those likely to receive the treatment under test. Knowledge of the selection criteria is needed in order to properly interpret a prescription or a consumption rate. The population at risk (those likely to receive the treatment under test) expressed in animal-years, rather than the total population, has been proposed to calculate the treatment rate [35]. In a dairy herd, only dairy cows during lactation (= susceptible to mastitis) are taken into account in studying drug consumption related to mastitis treatment. 
Apart from the physiological stage, other characteristics such as age and sex may influence drug consumption. These parameters can be taken into account in calculations of the prescription rate by weighting the reference population according to its socio-demographic characteristics. This method is adopted in economic analyses of medical prescriptions in Great Britain, with people older than 65 counting for three times more than younger subjects, or, alternatively, a more sensitive system based on both age and sex [28]. A similar system could be transposed to comparative studies of health expenditure or levels of drug use between farms to take herd structure, which may influence drug consumption, into account.

The annual increase rate (AIR) allows time series comparisons of the prescription of a drug.

$$
\mathrm{AIR}=\frac{\mathrm{P}_{\mathrm{n}+1}-\mathrm{P}_{\mathrm{n}}}{\mathrm{P}_{\mathrm{n}}} \times 100 \text {, in which } \mathrm{P}_{\mathrm{n}} \text { is }
$$

the number of prescriptions in the baseline year $[14,26]$. This can be used to show fluctuations in prescriptions between drugs or within a herd to highlight health defects.

\section{ANTIBIOTIC RESISTANCE}

Numerous studies in human medicine have shown that the use of antimicrobial agents selects resistant bacteria. Such studies have been conducted at the population level to show an ecological correlation, or for a particular association of specified antibiotic consumption, a given bacteria and a mechanism of resistance. Not all existing combinations have, as yet, been examined. Investigation of the epidemiological link between drug use and frequency of resistance has proved difficult. When using the epidemiological model developed by Austin et al. [8], it is crucial to know the prescription rate, the percentage of the community colonised, the length of exposure to treatment, the rate of prescription over time, the length of time required for colonisation by the bacteria and the duration of treatment, in order to link drug usage with resistance frequency. Selective pressure imposed by antibiotic use can be measured in defined daily dose/1000 inhabitants, equivalent to the proportion $a$ of the community receiving treatment ( $a=$ prescribing rate $\times$ treatment duration). In general, the equivalence between DDDs and antibiotic consumption is good in adult humans for which $a=0.5-1 \%$. Correspondence is, however, lower in children, in whom doses depend on age, and consumption is much more frequent than in adults $(=5 \%)$. This problem has to be taken into account in animal food production where body weight increase is rapid and several bacterial diseases have to be prevented or treated in young animals. In the epidemiological model developed by Austin et al. [8], one of the key parameters is the rate of selection of resistant bacteria in the treated population harbouring sensitive bacteria. For several bacteria, this rate should depend on the level of concentration obtained at the site of action and the antibacterial effect of the drug. For example, the selection of penicillin-resistant Streptococcus pneumoniae was linked with low dosage and long treatment duration [25]. The potency of a given dose will depend on the route of administration. Then again, for an antibiotic class such as tetracycline, two equivalent dosage regimens given by oral route, but for two different tetracyclines, will not be equivalent in terms of selection pressure for pharmacokinetic reasons [15].

\section{CONCLUSION}

To date, several units have been used, according to the purpose of the studies and available data. Commercial or economic information is expressed in financial units, firms tending to give total weights or amounts of items sold, whilst health authorities or researchers often use DDD. This should mean that all the units previously described do have not the same degree of 
usefulness. Descriptions of drug consumption in veterinary medicine could be carried out using all of them, but information given would not be the same.

The usefulness of the number of units dispensed is clear at the data collection stage when it occurs at the herd level, or for practitioners or pharmaceutical firms. But this unit has little relevance, as items do not contain the same amounts of drug. Translation into another unit is required to interpret purchases in order to describe consumption patterns, or evaluate antibiotic selective pressure and its evolution.

To describe consumption patterns in animal rearing, the use of cost units is frequent, probably because prices are easy to collect when recording units purchased and because health control costs are also a priority in animal medicine [19, 31, 32, 40]. But it is not a pertinent parameter for describing trends in the intensity of therapy. Prices change with time and rules governing them are quite complex. Prices and costs are certainly not good descriptors of drug consumption. A better approach to consumption could be progressively obtained from items purchased, translating them into weight of active substance and additional expression of activity such as equipotential doses or DDD. Weight of active substance at the herd or nation level allows international comparisons [43], or comparisons over time [47], to be made. But therapeutic effects and selective pressure in the event of antibiotic consumption studies could only be evaluated with units such as the DDD. DDD are the best solution when the objective is standardisation, but their definition presents a major difficulty in veterinary medicine [21]. Whilst waiting for the definition of such doses, equipotential dose could represent a useful compromise [37, 38].

Other measures, which were called "descriptive parameters" in this paper, do not accurately represent drug consumption in terms of quantity. They are, however, useful for determining consumption patterns within a population. The prescription rate or treatment rate, certainly difficult to obtain without a good method of recording drug administrations, should reflect health management habits and the selective pressure exerted on animals when focusing on antibiotics $[17,35]$. These parameters cannot be recommended at a nation level, in view of the difficulty involved in obtaining all the necessary information. Such parameters may be recommended for pharmaco-epidemiological studies when a small population or a few herds are surveyed to ascertain how drugs are respectively used. Today, purpose and design of studies are definitely the main selection criteria in choosing units of measurement.

Considerable difficulties are encountered, whatever the measuring unit, when attempting to obtain reliable statistics on the use of drugs. As well as units of measurement, standardised practices for measurement and presentation need to be developed. Even if they are difficult to describe, parameters such as population characteristics, or geographical or economical disparities, which could explain differences in patterns of drug consumption, must be mentioned. Findings emerging from studies of drug utilisation often serve scientific and economic purposes, such as the reduction of antimicrobial resistance, maintenance of health expenditure, or even evaluation of the impact of an intervention ban on antibiotic additives. The publication and communication of consumption data may give rise to debate or even polemics. Thus, as no standard yardstick is currently available for application to drug consumption, there is a need for skilful, complete and rigorous analyses, use of valid methodologies and caution in interpreting results.

\section{REFERENCES}

[1] Aarestrup F.M., Association between the consumption of antimicrobial agents in animal husbandry and the occurrence of resistant bacteria 
among food animals, Int. J. Antimicrob. Agents 12 (1999) 279-285.

[2] Agence du Médicament, Étude de la prescription et de la consommation des antibiotiques en ambulatoire, Observatoire National des Prescriptions et des Consommations des Médicaments, Mai, 1998, $39 \mathrm{p}$.

[3] Alfandari S., Bonenfant C., Depretere I., Beaucaire G., Le réseau de pharmaciens hospitaliers de l'ARECLIN, Mise en place d'un observatoire régional de consommation des antibiotiques hospitaliers dans le Nord-Pas-de-Calais, Bulletin Epidemiologique Hebdomadaire 14 (2000) 59-61.

[4] Anonymous, Utilisation des antibiotiques - Premières estimations en volume, La Revue de l'Alimentation Animale 520 (1998) 18-19.

[5] Anonymous, DANMAP 98 - consumption of antimicrobial agents and occurrence of antimicrobial resistance in bacteria from food animals, food and humans in Denmark, Danish Zoonosis Center, Copenhagen, July 1999.

[6] Anonymous, Bacterial resistance to antimicrobial agents in Finland FINRES 1999, Ministry of Agriculture and Forestry and Ministry of Social Affairs and Health, Helsinki, 1999.

[7] Anonymous, Antibiotic resistance in the European Union associated with therapeutic use of veterinary medicines, Report and quality risk assessment by the Committee for Veterinary Medicinal Products, EMEA, 14 July 1999.

[8] Austin D.J., Kristinsson K.G., Anderson R.M., The relationship between the volume of antimicrobial consumption in human communities and the frequency of resistance, Proc. Natl. Acad. Sci. USA 96 (1999) 1152-1156.

[9] Björnerot L., Franklin A., Tysén E., Usage of antibacterial and antiparasitic drugs in animals in Sweden between 1988 and 1993, Vet. Rec. 139 (1996) 282-286.

[10] Bogle S.M., Harris C.M., Measuring prescribing: the shortcoming of the item, Br. Med. J. 308 (1994) 637-640.

[11] Bories G., Louisot P., Rapport concernant l'utilisation d'antibiotiques comme facteurs de croissance en alimentation animale, 1998, $38 \mathrm{p}$.

[12] Bremón A.R., Ruiz-Tovar M., Gorricho P.B., de Torres B.P., Rodríguez L.R., Non-hospital consumption of antibiotics in Spain: 1987-1997, J. Antimicrob. Chemother. 45 (2000) 395-400.

[13] Carrie A.G., Zhanel G.G., Antibacterial use in community practice, Drugs 57 (1999) 871-881.

[14] Davey P.G., Bax R.P., Newey J., Reeves D., Rutherford D., Slack R., Warren R.E., Watt B., Wilson J., Growth in the use of antibiotics in the community in England and Scotland in 1980-93, Br. Med. J. 312 (1996) 613.

[15] del Castillo J.R.E., Martineau G.P., Besner J.G., Pharmacokinetic-pharmacodynamic inequivalence of chlortetracyline and oxytetracycline in pigs, Proceedings of the 8th EAVP Congress, Jerusalem, 30/07-3/08, $2000 \mathrm{~N}^{\circ} \mathrm{E} 6$.

[16] Dukes M.N.G., Drug utilization studies: methods and uses - Introduction, European series, WHO Regional Publications, Geneva, 45 (1993) $1-4$.

[17] Dunlop R.H., McEwen S.A., Meek A.H., Black W.D., Clarke R.C., Friendship R.M., Individual and group antimicrobial usage rates on 34 farrow-to-finish swine farms in Ontario, Canada, Prev. Vet. Med. 34 (1998) 247-264.

[18] FEDESA, Antibiotics for animals, A FEDESA perspective on antibiotics, Animal Health and the Resistance Debate, February 2000.

[19] Fourichon C., Seegers H., Beaudeau F., Verfaille L., Bareille N., Health control costs in dairy farming systems in western France, Livest. Prod. Sci. 68 (2001) 141-156.

[20] Gorse P., Janet C., Les anti-infectieux dans l'élevage, Recl. Méd. Vét. 159 (1983) 533-541.

[21] Grave K., Greko C., Nilsson L., Odensvik K., Mork T., Ronning M., The usage of veterinary antibacterial drugs for mastitis in cattle in Norway and Sweden during 1990-1997, Prev. Vet. Med. 42 (1999) 45-55.

[22] Grave K., Lingaas E., Bangen M., Rønning M., Surveillance of the overall consumption of antibacterial drugs in humans, domestic animals and farmed fish in Norway in 1992 and 1996, J. Antimicrob. Chemother. 43 (1999) 243-252.

[23] Greko C., Use of antibiotics for animals from 1980 to 1997, in: The Swedish Model of Animal Production - Information based on presentation at a seminar held in Stockholm 3-4 September 1998, Ministry of Agriculture Food and Fisheries Sweden, 1998, pp. 8-14.

[24] Guillemot D., Carbon C., Antibiotic use and pneumococcal resistance to penicillin: the French experience, Clin. Microbiol. Infect. 5 (1999) 4S38$4 \mathrm{~S} 42$.

[25] Guillemot D., Carbon C., Balkau B., Geslin P., Lecoeur H., Vauzelle-Kervroedan F., Bouvenot G., Eschwege E., Low dosage and long treatment duration of beta-lactam: risk factors for carriage of penicillin-resistant Streptococcus pneumoniae, J. Am. Med. Assoc. 279 (1998) 365-370.

[26] Guillemot D., Maison P., Carbon C., Balkau B., Vauzelle-Kervroëdan F., Sermet C., Bouvenot G., Eschwege E., Trends in antimicrobial drug use in the community - France 1981-1992, J. Infect. Dis. 177 (1998) 492-497.

[27] Hallas J., Nissen A., Individualized drug utilization statistics. Analysing a population's drug use from the perspective of individual users, Eur. J. Clin. Pharmacol. 47 (1994) 367-372.

[28] Harris C.M., Better feedback on prescribing for general practitioners, Editorial, Br. Med. J. 309 (1994) 356. 
[29] Harris C.M., Cullen J.W, Roberts D.J., Consider national standards for daily dosages, Br. Med. J. 308 (1994) 207.

[30] Hekster Y.A., Vree T.B., Goris R.J.A., Boerema J.B.J., The defined daily dose per 100 bed-days as a unit of comparison and a parameter for studying antimicrobial drug use in a university hospital, J. Clin. Hosp. Pharm. 7 (1982) 251-260.

[31] Kliebenstein J.B., Kirtley C.L., Selby L.A., A survey of swine production health problems and health maintenance expenditures, Prev. Vet. Med. $1(1982 / 1983)$ 357-369.

[32] Le Borgne M., L'analyse du poste dépenses de santé, Elevage et Rentabilité Mai (1995) IV-V.

[33] Lingaas F., Rønningen K., Epidemiological and genetical studies in Norwegian pig herds: I. Design of a disease recording system, Acta Vet. Scand. 31 (1990) 243-249.

[34] Lunde P.K.M., Baksaas I., Halvorsen T., Stromnes B., Oydvin K., The methodology of drug utilization studies. In: Bergman U., Grimson A., Welsterholm B., eds. Studies in drug utilization, WHO Regional Publications, European Series, Copenhagen 8 (1979) 17-28.

[35] Meek A.H., Martin S.W., Stone J.B., McMillan I., Britney J.B., Grieve D.G., The relationship among current management systems, production, disease and drug usage on Ontario dairy farms, Can. J. Vet. Res. 50 (1986) 7-14.

[36] Merlo J., Wessling A., Melander A., Comparison of dose standard units for drug utilisation studies, Eur. J. Clin. Pharmacol. 50 (1996) 27-30.

[37] Mudd A.J., Lawrence K., Walton J., Study of Sweden's model on antimicrobial use shows usage has increased since 1986 ban, Feedstuffs 70 (1998) 18.
[38] Mudd A.J., Lawrence K., Walton J., Animal usage of antimicrobials in Sweden 1986-1996 kg active substance or potency? Pig J. 43 (1999) 165-169.

[39] Ried L.D., Johnson R.E., Evaluation of the reliability and validity of a measure of anxiolytic druguse intensity for pharmacoepidemiologic studies, Ann. Pharmacother. 11 (1992) 1441-1446.

[40] Sans P., Guerin J.L., Prophylaxis methods and their costs in breeding and cramming of Mulard ducks (in French), Rev. Méd. Vét. 149 (1998) 149-154 .

[41] Taboulet F., Présentation d'une méthodologie permettant de mesurer en quantité et de comparer les consommations pharmaceutiques, Journal d’Économie Médicale 8 (1990) 37-63.

[42] Thrane N., Sorensen H.T., A one-year population-based study of drug prescriptions for Danish children, Acta Paediatr. 88 (1999) 1131-1136.

[43] Ungemach F.R., Figures on quantities of antibacterials used for different purposes in the EU countries and interpretation, Acta Vet. Scand. Suppl. 93 (2000) 89-98.

[44] van den Bogaard A.E., Antimicrobial resistance - relation to human and animal exposure to antibiotics, J. Antimicrob. Chemother. 40 (1997) 453461.

[45] Wessling A., Boëthius G., Measurement of drug use in a defined population. Evaluation of the defined daily dose (DDD) methodology, Eur. J. Clin. Pharmacol. 39 (1990) 207-210.

[46] WHO Collaborating Centre for Drug Statistics Methodology, Guidelines for ATC Classification and DDD Assignment, Oslo, Norway, 1996.

[47] Wierup M., Löwenhielm C., Wold-Troell M., Agenäs I., Animal consumption of antibiotics and chemotherapeutic drugs in Sweden during 1980, 1982 and 1984, Vet. Res. Comm. 11 (1987) 397405. 